\title{
Profesionalismo médico: aspectos históricos y religiosos
}

\author{
José Adolfo Rodríguez P1. \\ Medical professionalism: \\ Historical and religious aspects
}

The essence of the medical profession resides in the medical act, whereupon a sick human being meets another with the power to heal him or her. The source of this power has evolved from the divinity itself through magic to science or acquired knowledge. This power implies acknowledgement of values that are inherent to the profession as well as responsibility toward one's own conscience and toward society, elements considered constitutive of what we now call professionalism. From antiquity these principles have evolved into behavioral codes containing variable components according to the different ages and cultures, but also permenent core values such as respect for life, altruism, and honesty, among others. Scientific and technological advances have magnified medical power but at the same time they have required that the philosophical and ethical principles that ought to inform professional practice be made explicit. This happens at a time when certitudes are questioned or abandoned, relativism and secularism pervade culture, and traditional medical values are challenged. Therefore, consensus attainment appears for some as the only legitimation of the ethics of professional medical acts, while for others the ancestral principles and values of medicine have permanent validity as objective goods based on the dignity of the human person (Rev Méd Chile 2006; 134: 381-4).

(Key words: Ethics, medical; Practice management, medical; Professional practice)

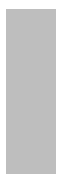

Recibido el 19 de julio, 2005. Aceptado el 2 de agosto, 2005.

Trabajo presentado en el Panel sobre Profesionalismo, en el XXVI Congreso Chileno de Medicina Interna, Viña del Mar, octubre de 2004.

${ }^{1}$ Departamento de Endocrinología, Escuela de Medicina. Facultad de Medicina, Pontificia Universidad Católica de Chile. Santiago de Chile.

Precedentes

El diccionario de la Real Academia Española de la Lengua define profesionalismo como "el cultivo o utilización de ciertas disciplinas, artes o deportes, como medio de lucron. Probablemente esto explica la reticencia de muchos médicos hispanohablantes para utilizar este término. El diccionario de

Correspondencia a: Dr. José Adolfo Rodríguez P. Departamento de Endocrinología, Escuela de Medicina. Pontificia Universidad Católica de Chile. Fax: 638-5675. E mail: jrodrigu@med.puc.cl la lengua inglesa de Oxford, en cambio, lo define como "la competencia o destreza esperada en un profesional". Sin embargo, ninguna de estas definiciones caracteriza bien lo que desde hace algún tiempo se debate intensamente en el mundo médico acerca de la profesión.

Para entender lo que se discute sobre profesionalismo médico es preciso comprender antes la naturaleza de la profesión médica y del trabajo médico. Para ello, parece necesario retroceder hasta llegar a lo más esencial de la profesión: el acto médico.

En este acto se encuentran dos seres humanos: uno en cuanto enfermo y otro en cuanto sanador, 
es decir, poseedor de un saber sobre lo que aqueja al primero y que desea aliviarlo. Cada uno de los protagonistas de este acto, y la interacción entre ellos, ha ido evolucionando con la historia y con las culturas. Ya en las épocas primitivas el papel del sanador o médico se fue diferenciando desde el del sacerdote, chamán o mago. El papel sanador del sacerdote se ejercía a través de la imploración a la divinidad, que podía actuar a través suyo. Su esfera "profesional", entonces, se circunscribía a las relaciones con la divinidad. El mago, en cambio, tenía como campo propio el conocimiento de conjuros que no imploraban sino que obligaban a la divinidad a actuar conforme a sus deseos. El médico, por su parte, si bien podía solicitar la ayuda de la divinidad, conocía más de la enfermedad y de tratamientos "naturales" para remediarla, lo que constituía su campo específico de acción ${ }^{1}$.

También, desde el período pre-técnico ha quedado en evidencia la enorme desigualdad entre los dos individuos presentes en el acto médico. El médico, en razón de su saber, puede curar pero también puede dañar y hasta matar: prerrogativas que las sociedades han ido reglamentando a través de la elaboración de códigos de justicia. En estos códigos primitivos, como el de Hammurabi, ya se esbozan conductas exigibles a los médicos y penas en caso de que no se cumplan. Esto supone ciertas responsabilidades de los médicos en cuanto a asegurarse competencia técnica para ejecutar sus acciones y asegurarse la confianza de sus enfermos, elementos que están en la raíz de un primitivo profesionalismo ${ }^{2}$.

Sin embargo, es a partir de unos 700 años antes de Cristo que empieza a configurarse una concepción de la medicina como un saber técni$\mathrm{co}$, que requiere dedicación, estudio y comprensión específicos y una especie de código de conducta esperable de quienes la ejercen como profesión.

\section{LA MEDICINA GRIEGA}

En la Grecia clásica comienza a definirse con mayor precisión el entorno de la práctica profesional médica y sus fundamentos filosóficos. En el acto médico puro y esencial, enunciado más arriba, se descubre un conjunto de circunstancias que definen mejor tanto al médico como al enfermo y que, en conjunto, colaboran a la curación. Sin pretender entrar con más detalle en este interesante tópico, sobre el cual hay abundantísima literatura, debo señalar algunas características que creo resultan especialmente relevantes para configurar lo que hoy llamamos profesionalismo médico. Una de ellas es la "phylía" o amistad entre médico y paciente, entendida no como familiaridad o compadrazgo sino, en la mentalidad helénica de entonces, como una corriente espiritual del uno hacia el otro que, a través de la curación de la enfermedad, tendía a restablecer la armonía de la naturaleza en el enfermo. Por parte del enfermo, esta "amistad" se expresaba como confianza, tanto en la ciencia y arte de la medicina como en la persona del médico en cuanto conocedor de esa ciencia y capacitado para usarla como arte en su curación ${ }^{3}$. Los médicos, por lo tanto, y para hacerse acreedores a esta confianza, debían actuar conforme a códigos esperables para la profesión para mantener y acrecentar su prestigio. En los escritos "Sobre el médico" y "Sobre la decencia", del Corpus Hippocraticum, se llega a recomendar hasta cómo deben vestirse y actuar los médicos, para hacerlo como diríamos hoy, con profesionalismo.

En cuanto a los aspectos religiosos, los griegos consideraban, desde el mito de Prometeo, que la ciencia había sido arrancada a los dioses. La medicina había sido enseñada por el Centauro Quirón a Asclepio, hijo de Apolo. Por esta conexión directa con la divinidad, el médico merecía la confianza del paciente y de todo individuo, pero sólo en la medida que, con su conducta profesional, demostrara ser digno de ella.

La ciencia médica, la «ekhné iatriké», estaba bien estructurada y requería largo tiempo de aprendizaje. Sin embargo, al lado de ella existía la simple práctica empírica, que no conocía el por qué ni el cómo de sus actos y que constituía una amenaza para el profesionalismo médico.

Por otra parte, la organización misma de la sociedad griega atentaba contra lo que hoy llamaríamos profesionalismo: el ejercicio de la medicina era discriminatorio, distinto según el estrato social del enfermo. Había una medicina para esclavos, otra para hombres libres; y dentro de ésta, era distinta la medicina para los hombres libres ricos y 
la medicina para pobres. A los esclavos no les atendían médicos educados sino rudos practicantes, casi siempre esclavos de médicos al lado de quienes habían aprendido alguna técnica. La comunicación verbal de éstos con el enfermo era mínima: "...a los esclavos los tratan por lo general los esclavos, ya sea corriendo de un lado a otro o permaneciendo en sus consultorios; ninguno de tales médicos da ni admite la menor explicación sobre la enfermedad de cada uno de estos esclavos, sino que prescribe lo que la práctica rutinaria le sugiere, como si estuviere perfectamente al tanto de todo y con la arrogancia de un tirano, y pronto salta de allí en busca de otro esclavo enfermo, y así alivia a su dueño del cuidado de atender a tales pacientes ${ }^{4}$.

En cambio, para los pacientes libres y ricos el tratamiento era exquisitamente individualizado a través del diálogo reconfortante y persuasivo, en el cual se inquiría no sólo sobre la enfermedad sino sobre la biografía del enfermo para indicar un tratamiento conforme a ella. Parte importante de éste era la dieta y el tiempo necesario para el reposo, del cual un pobre no podía disponer.

Ahora bien, ¿cuál era el papel de la religión en la práctica profesional griega? Las corrientes positivistas del siglo XIX han pintado la tecnificación de la medicina como una ruptura con la religión, proyectando sus deseos a la realidad investigada. Estudios posteriores menos prejuiciados, distinguen entre la religiosidad cultural, es decir relacionada con el culto a diferentes dioses, de raigambre cultural popular, y la religiosidad ilustrada, basada en la anterior pero enriquecida con la reflexión y la filosofía. Esta visión, frecuente en los círculos médicos más cultivados, tenía una concepción divina de la naturaleza, la physis, de la cual los diferentes dioses no eran más que personificaciones populares. Ambos tipos coexisten en las obras del Corpus Hippocraticum; la primera aparece más patente en las primeras líneas del Juramento: "Juro por Apolo médico, por Asclepio, por Hygeia.....5; pero, la segunda, se desprende de la mayoría de las demás en cuanto a que la recuperación de la salud no era más que restablecer la physis divina en su armonía y equilibrio.

El Juramento Hipocrático, a pesar de ser un documento compuesto en diferentes épocas y no un código universalmente aceptado ni practicado por la medicina griega, contiene ya elementos centrales del profesionalismo médico vigente hoy. Entre ellos destaca el respeto por la vida, menester médico por antonomasia. Junto a ello, la enumeración de deberes de los médicos con sus pacientes, redactadas en sentido negativo, como prohibiciones: no dañar ni hacer injusticia a los pacientes (primero el interés del paciente, justicia social); no dar drogas mortales ni abortivos a nadie (altruismo, competencia profesional, justicia, honestidad); no practicar la cirugía (atenerse a la propia competencia profesional), no abusar sexualmente del paciente ni de sus familiares (respeto, honestidad); no divulgar los secretos del paciente (confidencialidad).

\section{LA MEDICINA EN OCCIDENTE \\ TRAS LA IRRUPCiÓN DEL CRISTIANISMO}

Posteriormente la irrupción del Cristianismo trajo una profunda revolución en la manera de ver el mundo, lo que necesariamente involucró la relación médico-paciente, y una nueva expresión de los valores éticos del médico, hacia lo que hoy llamamos profesionalismo. Reducidos a su esencia, se considera que estos valores son "el amor a Dios sobre todas las cosas y al prójimo como a uno mismo", más aún, son expresión "del amor con que Cristo ama al hombrew. Esta concepción introduce, por una parte, un elemento sobrenatural que da sentido a la relación médico-paciente y, por otra, eleva a la condición de "prójimo" a todos los seres humanos. Tales valores han informado la práctica médica en Occidente desde entonces, vividos según el espíritu de los tiempos. Es así como en la Edad Media se crearon los hospitales donde se procuraba atender a aquellos enfermos antes abandonados, y el médico cumplía deberes religiosos, junto con los técnicos o civiles, para con sus pacientes.

Pero, muy pronto fueron separándose estas dos esferas de acción hasta llegar a los siglos XVII y XVIII en que la secularización empezó a establecerse firmemente en la cultura occidental, entendiendo por ella la eliminación de todo recurso a lo sobrenatural. Es indudable que la secularización y la racionalidad han sido utilísimas para el desarrollo de las ciencias, y en particular de la medicina. Sin embargo, la relación entre 
médico y paciente se ha visto amenazada en múltiples aspectos. Uno de ellos es en el interés que mueve al médico hacia el paciente, que ya no es, en muchos, solamente la phylía griega ni el amor cristiano, y ni siquiera el afán científico, sino tan sólo el afán de lucro. Otro es la "cosificación" del paciente, que deviene en un número o una enfermedad y no una persona. Así han surgido las poderosas amenazas que la profesión percibe hoy y que han llevado a la reflexión acerca de sus valores tradicionales, para derivar de ellos o dar nueva fundamentación a las conductas esperables en el cultivo de la profesión.

Por otra parte, el desarrollo científico ha llevado al médico a una situación de poder previamente insospechado ante la vida y la muerte, entre otros elementos por la manipulación genética y reproductiva, los trasplantes de órganos y la indefiniciones en los límites de la vida y de la muerte ${ }^{6}$. En ausencia de una visión religiosa o ética única sino, más bien, ante una visión agnóstica predominante o coexistiendo con múltiples y a veces minoritarias interpretaciones o creencias, se han desarrollado la bioética y la ética clínica procurando, también, tender un puente entre las visiones plurales. Pero sin un horizonte sobrenatural ni una verdad absoluta objetiva, sólo es posible avanzar, por ahora, hasta el nivel de los consensos. Se abre así un

\section{REFERENCIAS}

1. Sigerist HE. Primitive Medicine. En: Sigerist HE, Ed. A History of Medicine. New York: Oxford University Press, 1987; 105-213.

2. Zaragoza JR. La medicina de los pueblos mesopotámicos. En: Laín Entralgo, P: Historia Universal de la Medicina, Tomo I, Era pretécnica. Salvat Editores, Barcelona, 1972: 67-93.

3. Lain Entralgo P. Historia de la relación entre el médico y el enfermo. En: Laín Entralgo P. La peligroso terreno sujeto a los vaivenes del siglo, que podrían amenazar valores que la medicina ha defendido durante milenios.

¿Qué se puede esperar, en el siglo XXI, de la relación entre el médico y el paciente? La concepción de la economía casi como una religión en algunos círculos y el rebajamiento de la dignidad humana en aras de una eficiencia reducida a valorar sólo algunos de los elementos de la relación entre médico y paciente, como los aspectos técnicos o biológicos, llevan a considerar a la medicina como una empresa productiva más, cuyos resultados son más fácilmente mensurables en términos numéricos que en calidad humana o relación interpersonal. Por lo tanto, el ejercicio de la medicina como profesión se ve seriamente amenazado de extinción, frente a su proliferación como oficio asalariado de alto contenido científico tecnológico. ¿Volveremos, tal vez, al ejercicio de la medicina para esclavos de la Grecia antigua? Ante tal pesimista escenario, la profesión reclama rescatar, de sus orígenes, sus virtudes ancestrales; lo que, en versión secularizada, se llama "profesionalismo", pero que comprende, integra y hace relevantes los valores más hondos y tradicionales con que la evolución y la historia de la humanidad ha, siempre, destacado el ejercicio profesional de un acendrado humanismo.

relación médico-enfermo. Madrid: Alianza Editorial, 1983: 31-201.

4. Platón. Las leyes, o de la legislación. En: Platón, Obras Completas. Madrid: Aguilar SA de Ediciones, 1969: 1274-520.

5. Hipócrates. Juramento. Sobre el médico. Sobre la decencia. En: Tratados hipocráticos I. Madrid: Editorial Gredos, 1983: 77-78, 175-182, 195-210.

6. SEIFERT J. The philosophical diseases of Medicine and their cure. En: Philosophy and Medicine, Vol. 82. Dordrecht: Springer, 2004. 